\title{
Application of Artificial Neural Networks in the Context of Active Magnetic Bearing Control Systems
}

\author{
Alexander Kravtsov \\ Department of Electric Power \\ Engineering, Electric Drive and \\ Automation Systems \\ Pskov State University \\ Pskov, Russia \\ avkravtsov@inbox.ru> \\ Igor Savraev \\ Department of Electric Power \\ Engineering, Electric Drive and \\ Automation Systems \\ Pskov State University \\ Pskov, Russia \\ igor_savraev@mail.ru
}

\author{
Konstantin Vukolov \\ Department of Electric Power \\ Engineering, Electric Drive and \\ Automation Systems \\ Pskov State University \\ Pskov, Russia \\ kasyanvukolov@yandex.ru \\ Sergey Loginov \\ Department of Electric Power \\ Engineering, Electric Drive and \\ Automation Systems \\ Pskov State University \\ Pskov, Russia \\ lsy1@mail.ru
}

\author{
Igor Plokhov \\ Department of Electric Power \\ Engineering, Electric Drive and \\ Automation Systems \\ Pskov State University \\ Pskov, Russia \\ igor_plohov@list.ru
}

\begin{abstract}
The article is devoted to the application of neural network methods and genetic algorithms in solving problems of controlling an electric drive of an active magnetic suspension. The method of rolling moment for eliminating an imbalance is considered. The scheme of the neural network controller and the curves of the transients in the open single-mass electromechanical system and in the system c of the neurocontrollers are presented.
\end{abstract}

Keywords - Active magnetic bearing, neural network the neural network controller, transient simulation.

\section{INTRODUCTION}

Active magnetic bearing (AMB) is a complex mechatronic device, which makes it possible to achieve the noncontact suspension of electric machine rotor towards a stator. The process of fitting the stable rotor position is accomplished by the magnet gravity power, that influences the rotor from the side of electromagnets [1]. The AMB control loop configures the current in magnet coils, according to measures from the rotor displacement sensors or by the signal from magnetic flux sensor. The primary advantages of an AMB system are meant to be relatively high carrying capacity, high-level mechanical resistance, ability to gain a persistent non contact body bearing, a broad range to vary stiffness and buffering and opportunity to apply the AMB system in cases of high-speed rotation, in low and high temperatures. Negative points of applicable AMB devices are the large cost of a final target device and the high complexity of both system engineering and controller implementation [2].

There is a number of issues, which could finally get a resolution and thus make it possible to reduce both engineering self-cost and operation cost. One of such issues is the minimisation of human labour from the perspective of system design and operational process. The other relevant problem is the complete AMB diagnostic system synthesis. These above-described topics can be considered in terms of artificial intelligence, including neural network application, that now becomes common use in control system realisations and in diagnostics of electromechanic facilities. 


\section{REVIEW OF CURRENT INVESTIGATIONS IN THE PROBLEM SPACES}

A. Modern view on electromechanic system diagnostics and operation using neural network technologies

One of the viable approaches in order to improve the inspection system functional efficiency and to achieve better AMB diagnostics could be the application of complex intelligent computer technologies. The idea of NN usage in terms of gaining required diagnostic and propagation results leads to a sufficient attenuation of the electromechanical system diagnostics process. The ways of neural network usage in the electromechanical diagnostics systems are listed below:

- NN application for parameter-oriented valuation of AMB elements. Here NN provides the ability to compare the current AMB state and the non-defect element model.

- NN application for electromagnetic system parameters propagation. Developing appropriate techniques allows to formulate variable relations as polynomials.

- $\mathrm{NN}$ application in pattern recognition systems. NN provides a common classification of an equipment state, namely the distribution of the current state to one of state classes (accurate or inaccurate with a concrete defect type), that is rated by the given trial type or measure type.
NN application in diagnostics and in electromechanic facility propagation tasks carries out these several positive points:

- For neural network algorithm implementation the minimum of object info is required.

- In case if NN synthesis it is possible to evaluate a parallel information processing, that, firstly, improves the system operational speed, and, secondly, leads to a higher system reliability [3].

\section{B. Direct electric motor torque control using a neural network}

One of the vital issues in electrical motors area is the problem of current control systems modification via new non-conventional approaches and control algorithms, which could be artificial neural networks (NN) and fuzzylogic. Among these are the NN stator flux-linkage observer and the special direct torque control device, published in IJAREEIE [4, 5].

The main difference of the fuzzy-logic direct control system in respect of the traditional one, based on an optimized switch table, is that there occurs a neural block that identifies the electrical motor parameters and the parameters of a rotation speed fuzzy controller, see Figure 1. The duty of the neural network block is to calculate electromotor characteristics [6]. The neuro-fuzzy controller appears to be an artificial neural network, that is trained by the regular laws of rotor rotation speed proportionalintegral controller.

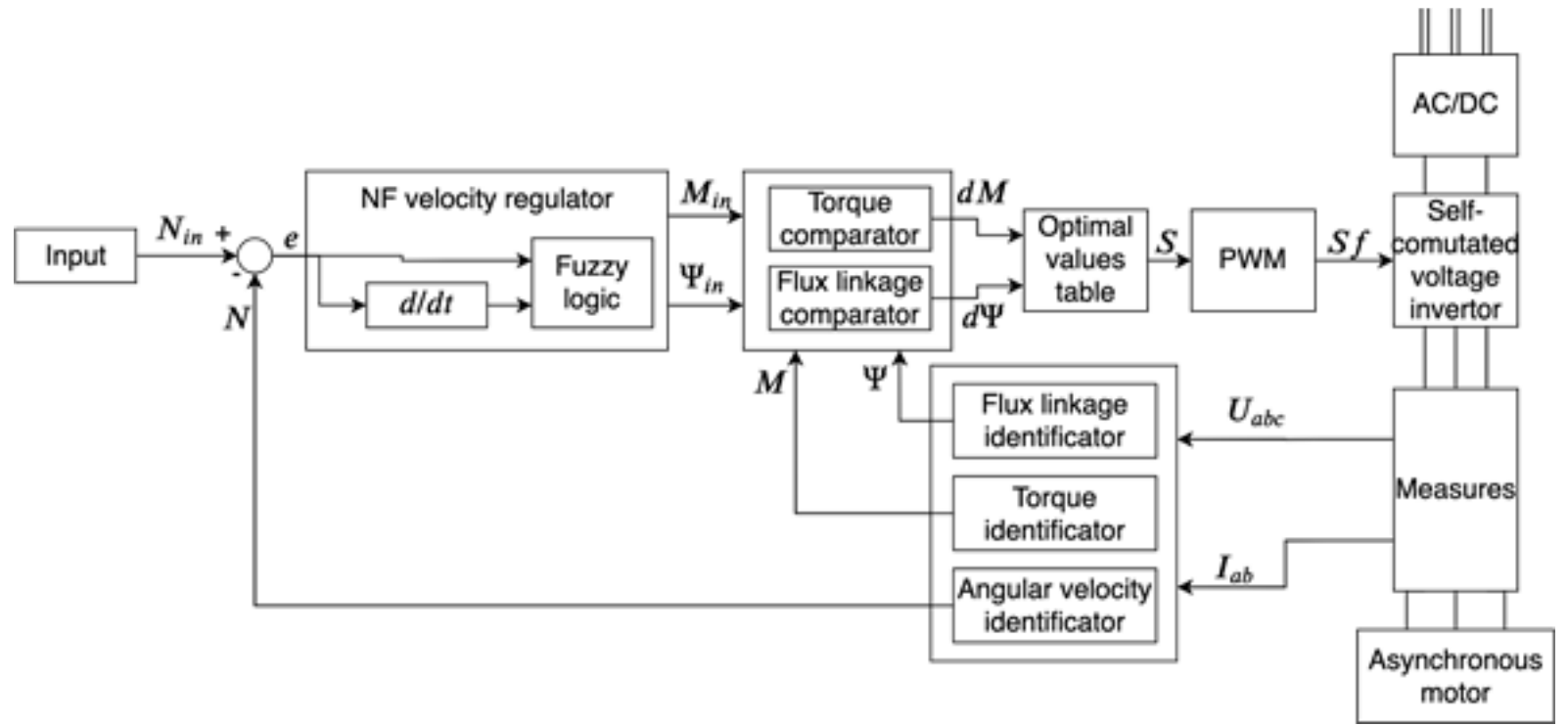

Fig. 1. An asynchronous motor control system with neural network block, $\mathrm{N}_{\text {in }}$ - velocity threshold, $\mathrm{N}$ - rotor velocity, $\psi$ - magnetic flux, $\mathrm{M}$ - torque on the motor shaft, S - control signal, Sf - modulated signal, U - motor coil voltage, I - motor coil current.

The main difference of the fuzzy-logic direct control system in respect of the traditional one, based on an optimized switch table, is that there occurs a neural block that identifies the electrical motor parameters and the parameters of a rotation speed fuzzy controller, see Figure 1. The duty of the neural network block is to calculate electromotor characteristics [6]. The neuro-fuzzy controller appears to be an artificial neural network, that is trained by the regular laws of rotor rotation speed proportionalintegral controller.

The rotor rotation speed controller provides better quality and higher speed of the transient process. Therefore, the combination of fuzzy controller and 
parameters identifier block in the electrical motor system would lead to the speed improvement of the controller itself, as well as to higher adaptiveness due to data integrating.

\section{AMB control torque method using multilayer perceptrons}

The current discovery is about the neural network application in terms of AMB control with torque method. This new method can be applied to the active magnetic bearing in order to eliminate the unbalance [7].

Torque method is used for training the NN with the aim to minimize the error between an estimated model and the real model of the AMB. The dynamic equation of the AMB is given by (1) [8].

$$
D(q) \ddot{q}+h(q \cdot \dot{q})+T=u
$$

where $D$ - tensor of inertia, $q$ - rotor position matrix, h rotor Coriolis matrix, $T$ - rotor mechanical energy, $U$ external torque matrix.

Since there are always uncertainties, the ideal error response cannot be achieved in general. The neural network controller is introduced to compensate these uncertainties.

The new control law can be written as (2).

$$
u(t)=\widehat{D}(q) v(t)+\widehat{h}(q, \dot{q})+\tau_{n}
$$

where $v$ - rotor acceleration matrix, $\tau_{n}$ - neural network output value, $u(t)$ - control signal.

The NN output $\tau_{n}$ cancels out the uncertainties caused by the inaccurate model in the computed torque controller. [9].

The NN controller scheme is depicted on the Figure 2

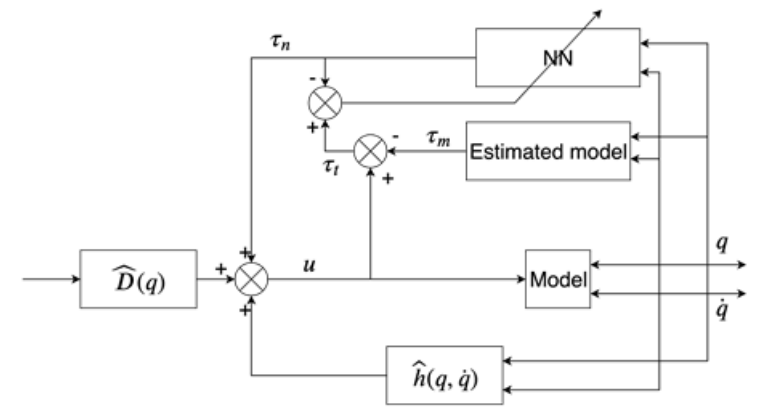

Fig. 2. Representation of the neural network controller, $\tau_{n}$ - neural network output, $u$ - rotor external moment matrix, $\tau_{m}$ - math model output, $\tau_{t}=u-\tau_{m}, \hat{D}$ - estimated tensor of inertia, $\hat{h}$ - estimated rotor Coriolis matrix, $q$ - rotor position matrix

Current study discovers the performance of the proposed NN controller. System temporal responses are investigated via modelling both standard PID-controller and the NN controller in Matlab. The process is modelled on five AMB axes, three choices of estimated model are highlighted. Figure 3 shows, for instance, the results for the variable estimated model.

Simulations done in the study show very clearly the improvement of responses by NN controller for a magnetic bearing under a computed torque control, compare with classical controllers.

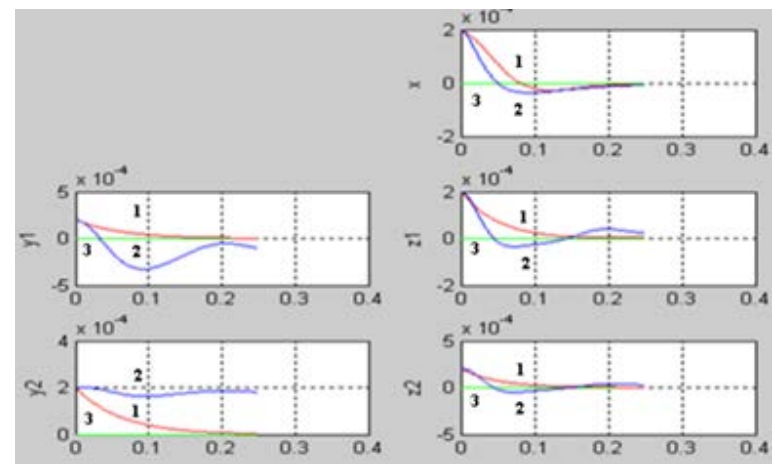

Fig. 3. Diagram representing the answers on the five axes for the variable estimated model, in red-1: System with MLP, in blue-2: PID alone, and in green-3: the desired answer

D. The application of NN approaches and genetic algorithms in objectives of electric motor control

Although the existing approaches of electromotor automatic control system synthesis, as, for instance, modal control approach, make it possible to develop wellcontrolled systems, the practical realization of such systems leads to a variety of technical problems. These are namely the necessity to get hard-to-measure control variables (such as the moment of elasticity) and in some cases the inability to built synthetic parameters in practice because of restrictions, that exist on real electrical motors. The replacement of linear controllers that are in service with non-linear ones can provide the proper output control response using less signal-from-coordinate dependencies. The opportunity for such a replacement is achieved owing to a non-linear controller, designed as the neural controller, which is actually a neural network (NN) [10].

In current topic the usage of $\mathrm{NN}$ and genetic algorithms with electrical motor devices lies over the concrete object assignment, which is about suppressing the self-excited frictional oscillations in electromechanic set-ups with a non-linear friction pair load.

With the NN usage, the solution is based on a single feedback of an easy measured axis, and such NN approach provides, apart from the steadiness, both the motor axis limitations required and the transient process quality.

As result there is a stable configuration build, transient processes of the system are depicted in Figure 4. Auto oscillation is gone and dynamical quality indexes are quite good enough. 

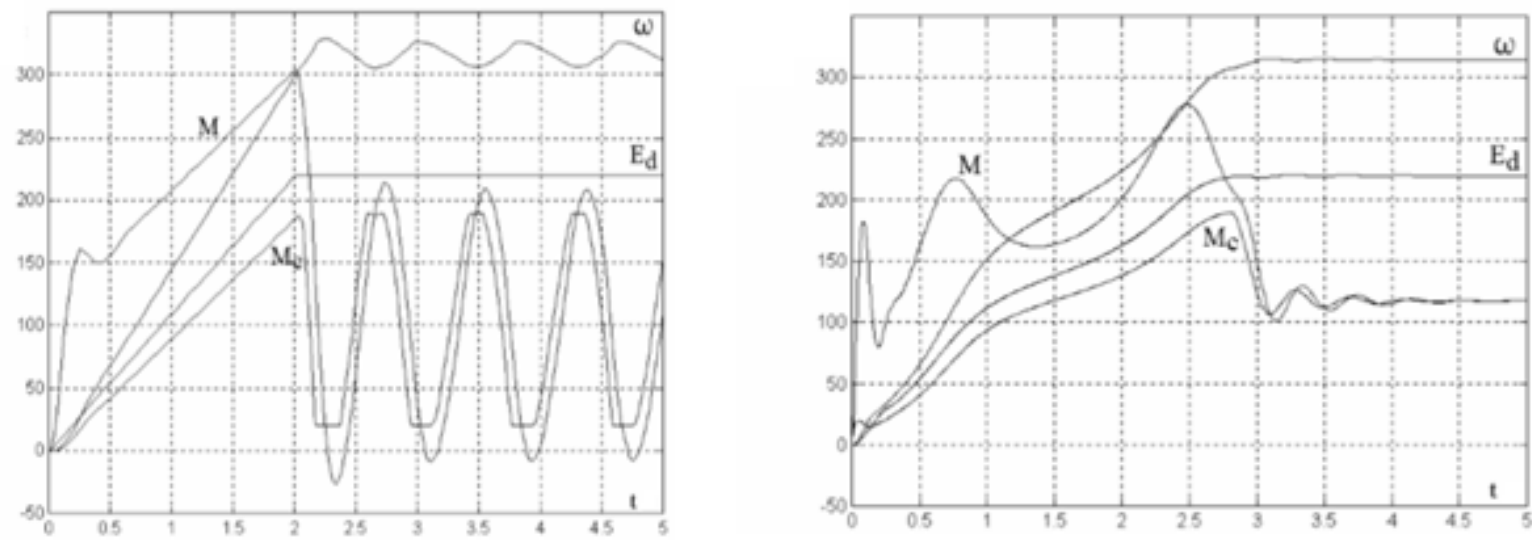

Fig. 4. Transient responses in the open-loop electromechanical configuration (on the left) and in the NN controller system (on the right), $M$ - control torque, $M_{c}$ - friction pair load, $E_{d}$ - control signal, $\omega$ - rotor velocity, $\mathrm{t}$ - time.

\section{CONCLUSIONS AND PERSPECTIVES}

From the point of current discovery, it can be concluded, that a variety of investigations is being done in the area of NN application in electromechanic control and electromechanic diagnostics. Nevertheless, AMB control and $\mathrm{AMB}$ parameters optimization using $\mathrm{NN}$, as well as NN usage in AMB diagnostics are quite unexplored and have a large potential for future investigations, so the researches and development in this area are certainly relevant.

\section{REFERENCES}

1. Zhuravlev U.N. Activnye magnitnye podshipniki: teoriya, raschet, primenenie [Active magnetic bearings: theory, calculations, application]. Saint-Petersburg.: Politekhnica Publ., 2003. pp. 22-30. (in Russian).

2. Bleuler H. Magnetic levitation: a challenge for control design in mechatronics. Toshiba Chair for Intelligent Mechatronics, 2011. pp. 578583.

3. Bobokin G.I., Shprekher D.M. Primenenie neyronnykh setei dlya diagnostiki elektromekhanicheskikh sistem [Neural networks application in the field of electromechanical system diagnostics], 2003. Available at: https://cyberleninka.ru/article/n/primenenie-neyronnyh-setey-dlyadiagnostiki-elektromehanicheskih-sistem (in Russian).

4. Wang Ping, Li Bin, Huang Ruixiang, Li Guidan. Diangong jishu xuebaoTrans. China Electrotech, 2003. pp.5-8.

5. Gottapu K., Prashanth Y., Mahesh P., Sumith Y. Simulation of DTC IM Based on PI\& Artificial Neural Network Technique. International Journal of Advanced Research in Electrical, Electronics and Instrumentation Engineering vol. 2, no. 7, issue 7, 2013.

6. Mamdani E.H., Assilian S. An experiment in linguistic synthesis with a fuzzy logic controller. Int. J. Man-Mach. Stud., vol. 7, pp.1-13, 1975.

7. F. Matsumura and T. Yoshimoto. System modeling and control design of horizontal shaft magnetic bearing system. IEEE Trans. Magn., vol. Mag-22, no. 5, 1986.

8. K. Noami and H. Yamaguchi. Robust control of magnetic bearing systems by means of sliding mode control. Proc. Int. Symp. Applicat. Electromagnetism, vol. ISEM 91, no. 1, 1991.

9. J. De Miras, A. Charara, B. Caron. Nonlinear control of a magnetic levitation system without premagnetization. IEEE Transactions on Control Systems Technology, vol.4, no.5, 1996, pp.513-523.

10. Narendra K.S., Parthasarathy K. Identification and control of dynamical systems using neural networks. IEEE Trans. on Neur. Net, vol. 1 , no. 1,1990 , pp. $4-27$. 